\title{
To Study the endoscopic colonic biopsies of patients presenting with chronic watery diarrhea or constipation with special emphasis on microscopic colitis
}

\author{
Dr. Hrushikesh S Kolhe, Dr. S. D. Mahore, Dr. Samir S Patil, Dr. Revati N Patil \\ N. K. P. Salve Institute of Medical Sciences and Lata Mangeshkar Hospital, Nagpur.
}

\section{Introduction}

Chronic diarrhea is defined as a decrease in fecal consistency lasting for four or more weeks. ${ }^{1}$ Prevalence of chronic diarrhea varies in different populations but a reasonable approximation is that it affects about $5 \%$ of the population. ${ }^{2-4}$ Chronic diarrhea is one of the challenges of gastroenterology. Though well studied in pediatric age group, it has received little attention as a subject of research in adult population in India. Although no statistical data are available, chronic diarrhea is frequently seen in clinical practice in our part of the country. A number of disorders are associated with chronic diarrhea. The prevalence of specific disorders varies based upon the practice setting. ${ }^{1}$

Colonoscopy is the most widely used diagnostic method to study the colon and has the highest diagnostic sensitivity and specificity of all available tests. In most studies, $90 \%$ to $95 \%$ of the colon can be examined. The examination has an extremely small risk of complications ( $0.1 \%$ to $0.2 \%$ risk of bleeding or perforation). Colonoscopy with biopsy is an important part of diagnostic work up in cases of chronic diarrhea especially to rule out structural and occult inflammatory disease. ${ }^{5}$ Studies have shown that a significant proportion of causes of chronic diarrhea lie in the large bowel which can be diagnosed by endoscopy and biopsy of the lesions. ${ }^{6,7}$

During endoscopy, multiple biopsies are often necessary to diagnose various pathologic conditions including cancer. Currently, we can routinely differentiate malignant from benign lesions according to the endoscopic finding. Furthermore, with the development of the video-endoscope instrument, we could get a wider vision, and better targeting to the suspicious lesion, that leads to a reduced number of biopsy specimens needed to diagnose colonic pathological conditions.

Purpose of the current study was to determine the frequency of large bowel causes of chronic diarrhea and hence to evaluate the usefulness of colonoscopy in the diagnosis of chronic diarrhea.

Also very few studies have been done on microscopic colitis in our part of the world, as we got very few references in the literature. So we put special emphasis on cases diagnosed as microscopic colitis.

Colitis is a term used to describe the inflammation of the colon. There are a variety of causes of colitis including infections, poor blood supply and autoimmune reactions.

In 1980, Read et al ${ }^{8}$ introduced microscopic colitis characterized by chronic diarrhea with normal endoscopic and radiologic findings, but with increased colonic mucosal inflammatory cells and epithelial lymphocytic infiltration on histologic examination. Later,

Levison et $\mathrm{al}^{9}$ emphasized that microscopic colitis covered all cases of colitis with normal colonoscopy, but abnormal histopathologic features and described lymphocytic

colitis separately. Collagenous colitis, which is a closely related condition, was first described in 1976 as a separate subtype with additional histological finding of increased subepithelial collagen band thickness. ${ }^{10}$ Thus, microscopic colitis is a condition with two subtypes having similar clinical, but different histological characteristics. The prevalence of microscopic colitis has been difficult to estimate.

Microscopic colitis is characterized by intermittent, secretory diarrhea in older patients, although persons of all ages can be affected. ${ }^{11}$ It should be suspected in older patients with persistent, often nocturnal diarrhea that does not respond to fasting. It is thought to be fairly common, comprising 10 percent of chronic diarrhea cases. ${ }^{11}$

Ulcerative Colitis occurs with equal frequency in both sexes. ${ }^{1}$ It appears most often in patients between 20 and 30 years of age with a second peak between 70 and 80 years of age. Etiology is unknown.

Crohn's disease involves the large bowel in $40 \%$ of all cases, with or without a concomitant ileal component. Etiology is undetermined.

Other conditions like Ischemic colitis, Infectious colitis (non-specific bacterial, tuberculous, viral, amoebic,) pseudomembranous, eosinophilic colitis have also been included in this study as their clinical presentation is similar to above mentioned conditions. They have been discussed in detail in the later parts of this study.

\section{Material and Methods:}

The study was carried out in our hospital for a period of 2 years, between 2011- 2013. The study was of cross- sectional based type.

Patients presenting with lower abdominal symptoms (Pain, diarrhea, abdominal cramps, tenesmus, and constipation) were included. A total of 122 such patients including both inpatients and outpatients were investigated thoroughly about their dietary habits (Veg or Non-Veg diet), history of smoking, drug history (ex. 
NSAIDS, drugs for constipation etc.). Patients with previous history of malignancy or those diagnosed later after histopathological evaluation were excluded.

Routine and special staining by Hemotoxylin and Eosin, Masson's Trichome, PAS and Immunostaining with CD3 marker was done as required.

Statistical analysis was done by using inferential statistics using chi-square test and descriptive statistics using mean, SD, frequency and percentage. Software used in the analysis was SPSS 17.0 and Graph Pad Prism 5.0 version, $\mathrm{p}<0.05$ was considered as level of significance.

\section{Observations And Results:}

A total of 122 patients fulfilling the above mentioned criteria (chronic watery diarrhea or intermittent constipation) were examined and their biopsies studied. Out of these 2 cases were diagnosed for malignancy, so they were excluded from the study. So a total of 120 cases were included for statistical analysis.

Table 1: Distribution of patients according to Presenting complaints

\begin{tabular}{|l|l|l|}
\hline Presenting Complaints & No of patients & Percentage \\
\hline Pain in abdomen & 29 & 24.17 \\
\hline Watery Diarrhea & 120 & 100.00 \\
\hline Fever & 36 & 30.00 \\
\hline Abdominal Discomfort & 25 & 20.83 \\
\hline Intermittent Constipation & 13 & 10.83 \\
\hline
\end{tabular}

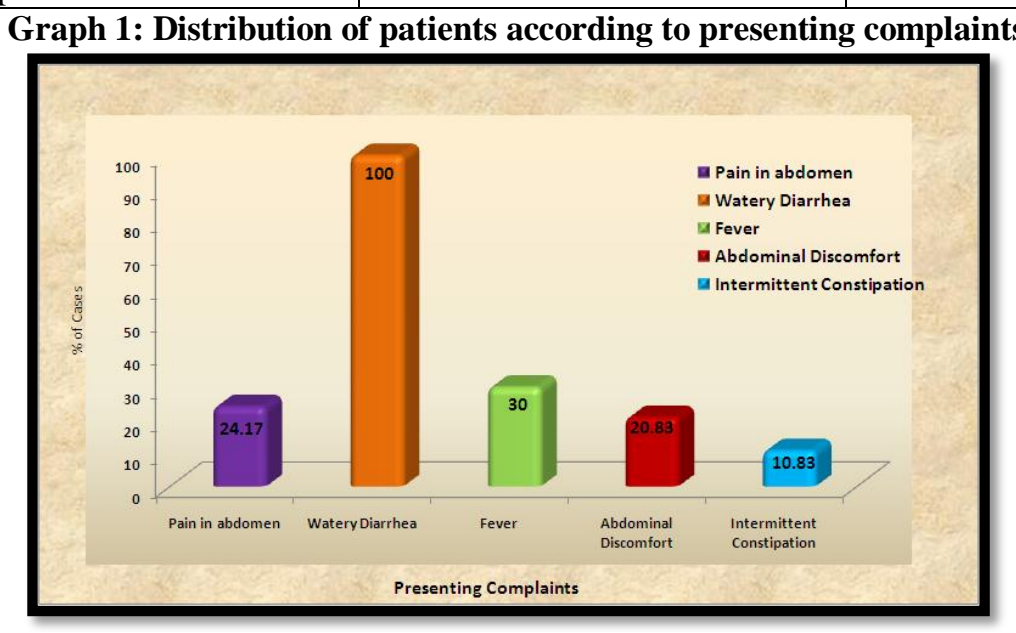

Table 2: Distribution of patients according to Histopathological Impression

\begin{tabular}{|l|l|l|}
\hline Histopathological Impression & No of patients & Percentage \\
\hline Acute Nonspecific Colitis & 72 & 60.0 \\
\hline Ulcerative Colitis & 20 & 16.7 \\
\hline Tuberculosis - Intestine & 9 & 7.5 \\
\hline Crohn's Disease & 7 & 5.8 \\
\hline Pseudo-membranous Colitis & 6 & 5.0 \\
\hline Amoebic Collitis & 3 & 2.5 \\
\hline Microscopic Collitis & 2 & 1.7 \\
\hline Eosinophilic Collitis & 1 & 0.8 \\
\hline Total & 120 & 100.00 \\
\hline
\end{tabular}

After thoroughly going through the histopathological features of the biopsies obtained from the patients we recorded that maximum number of cases were of Acute Non- specific colitis recording i.e. $60 \%$ of the total cases, followed by Ulcerative Colitis, Tuberculosis-intestine, Crohn's disease, pseudo-membranous colitis, amoebic colitis, microscopic colitis and eosinophilic colitis in order of their frequency.

Both men and women among the study population were equally affected with pseudo-membranous colitis and microscopic colitis, with 3 cases and 1 case each i.e. $2.50 \%$ and $0.83 \%$ respectively.

One case of eosinophilic colitis was found in a 33 year old man who presented with a single symptom of chronic watery diarrhea.

Majority of patients fell between the age group of a range between 25-54 years of age. Patients between 25-34 age group were 34(28.3\%), while between 35-44 years 40(33.3\%) and between 45-54 years 34(28.3\%).

A detailed history of personal habits such as smoking, vegetarian or non- vegetarian diet, Alcohol intake, Drug history was taken and their association with the histopathological impression was calculated. 
To Study the endoscopic colonic biopsies of patients presenting with chronic watery diarrhea ....

Table 3: Association of history of smoking with Histopathological Impression

\begin{tabular}{|l|l|l|}
\hline \multirow{2}{*}{ Histopathological Impression } & Smoking & Absent \\
\cline { 2 - 3 } & Present & $40(55.55 \%)$ \\
\hline Acute Nonspecific Colitis & $32(44.44 \%)$ & $5(25 \%)$ \\
\hline Ulcerative Colitis & $15(75 \%)$ & $2(22.22 \%)$ \\
\hline Tuberculosis - Intestine & $7(77.77 \%)$ & $2(28.57 \%)$ \\
\hline Crohn's Disease & $5(71.42 \%)$ & $2(33.33 \%)$ \\
\hline Pseudo-membranous Colitis & $4(66.66 \%)$ & $1(33.33 \%)$ \\
\hline Amoebic Collitis & $2(66.66 \%)$ & $2(100 \%)$ \\
\hline Microscopic Collitis & $0(0 \%)$ & $0(0.00 \%)$ \\
\hline Eosinophilic Collitis & $1(100 \%)$ & $54(45 \%)$ \\
\hline Total & $66(55 \%)$ & \\
\hline N2-value & 10.69 & \\
\hline p-value & $0.15, \mathrm{NS}, \mathrm{p}>0.05$ & \\
\hline
\end{tabular}

Table 4: Association of drug intake history with Histopathological Impression

\begin{tabular}{|c|c|c|}
\hline \multirow{2}{*}{ Histopathological Impression } & \multicolumn{2}{|c|}{ Drug Intake History } \\
\cline { 2 - 3 } & Present & Absent \\
\hline Acute Nonspecific Colitis & $10(13.88 \%)$ & $62(86.11 \%)$ \\
\hline Ulcerative Colitis & $1(5 \%)$ & $19(95 \%)$ \\
\hline Tuberculosis - Intestine & $0(0 \%)$ & $6(100 \%)$ \\
\hline Crohn's Disease & $1(14.28 \%)$ & $0(85.71 \%)$ \\
\hline Pseudo-membranous Colitis & $6(100 \%)$ & $0 \%$ \\
\hline Amoebic Collitis & $0 \%$ & $2(100 \%)$ \\
\hline Microscopic Collitis & $0 \%$ & $1(100 \%)$ \\
\hline Eosinophilic Collitis & $0 \%$ & $102(85 \%)$ \\
\hline Total & $18(15 \%)$ & \multicolumn{2}{|c|}{32.17} \\
\hline N2-value & \multicolumn{2}{|c|}{$\mathrm{P}<0.0001$, Significant } \\
\hline p-value & \multicolumn{2}{|c}{} \\
\hline
\end{tabular}

Table 5: Association of history of dietary habits with Histopathological Impression

\begin{tabular}{|c|c|c|}
\hline \multirow{2}{*}{ Histopathological Impression } & \multicolumn{2}{|c|}{ History of dietary habits(Non-veg diet) } \\
\cline { 2 - 3 } & Present & Absent \\
\hline Acute Nonspecific Colitis & $47(65.27 \%)$ & $25(34.72 \%)$ \\
\hline Ulcerative Colitis & $8(40 \%)$ & $12(60 \%)$ \\
\hline Tuberculosis - Intestine & $3(33.33 \%)$ & $6(66.66 \%)$ \\
\hline Crohn's Disease & $5(71.42 \%)$ & $2(28.57 \%)$ \\
\hline Pseudo-membranous Colitis & $0 \%$ & $6(100 \%)$ \\
\hline Amoebic Collitis & $0 \%$ & $3(100 \%)$ \\
\hline Microscopic Collitis & $2(100 \%)$ & $0 \%$ \\
\hline Eosinophilic Collitis & $0 \%$ & $1(100 \%)$ \\
\hline Total & $65(54.17 \%)$ & $55(45.83 \%)$ \\
\hline א2-value & \multicolumn{2}{|c|}{0.014, Significant } \\
\hline p-value & \multicolumn{2}{|c}{} \\
\hline
\end{tabular}

Table 6: Association of Pain in Abdomen with Histopathological Impression

\begin{tabular}{|c|c|c|}
\hline \multirow{2}{*}{ Histopathological Impression } & \multicolumn{2}{|c|}{ Pain in abdomen } \\
\cline { 2 - 3 } & Present & Absent \\
\hline Acute Nonspecific Colitis & $14(19.44 \%)$ & $58(80.55 \%)$ \\
\hline Ulcerative Colitis & $9(45 \%)$ & $11(55 \%)$ \\
\hline Tuberculosis - Intestine & $0(0.00 \%)$ & $9(100 \%)$ \\
\hline Crohn's Disease & $3(42.85 \%)$ & $4(57.14 \%)$ \\
\hline Pseudo-membranous Colitis & $2(33.33 \%)$ & $4(66.66 \%)$ \\
\hline Amoebic Collitis & $1(33.33 \%)$ & $2(66.66 \%)$ \\
\hline Microscopic Collitis & $0(0.00 \%)$ & $2(100 \%)$ \\
\hline Eosinophilic Collitis & $0(0.00 \%)$ & $1(100 \%)$ \\
\hline Total & $29(24.17 \%)$ & $91(75.83 \%)$ \\
\hline w2-value & \multicolumn{2}{|c|}{$0.12, \mathrm{NS}, \mathrm{p}>0.05$} \\
\hline p-value & \multicolumn{2}{|c|}{} \\
\hline
\end{tabular}


To Study the endoscopic colonic biopsies of patients presenting with chronic watery diarrhea ....

Table 7: Association of Abdominal Discomfort with Histopathological Impression

\begin{tabular}{|c|c|c|}
\hline \multirow{2}{*}{ Histopathological Impression } & \multicolumn{2}{|c|}{ Abdominal Discomfort } \\
\cline { 2 - 3 } & Present & Absent \\
\hline Acute Nonspecific Colitis & $12(16.66 \%)$ & $12(60 \%)$ \\
\hline Ulcerative Colitis & $8(40 \%)$ & $8(8.88 \%)$ \\
\hline Tuberculosis - Intestine & $1(11.11 \%)$ & $5(71.42 \%)$ \\
\hline Crohn's Disease & $2(28.57 \%)$ & $4(66.66 \%)$ \\
\hline Pseudo-membranous Colitis & $2(33.33 \%)$ & $3(100 \%)$ \\
\hline Amoebic Collitis & $0 \%$ & $2(100 \%)$ \\
\hline Microscopic Collitis & $0 \%$ & $1(100 \%)$ \\
\hline Eosinophilic Collitis & $0 \%$ & $95(79.17 \%)$ \\
\hline Total & $25(20.83 \%)$ & 8.25 \\
\hline v2-value & \multicolumn{2}{|c|}{$0.31, \mathrm{NS}, \mathrm{p}>0.05$} \\
\hline
\end{tabular}

\section{Discussion:}

Most common causes of large gut chronic diarrhea in this study population are acute non- specific colitis $(60 \%)$ and ulcerative colitis (16\%). It is generally agreed that common causes of chronic diarrhea in the developing countries are bacterial, mycobacterial and parasitic infections. ${ }^{12}$ However results of the present study shows that ulcerative colitis is also responsible for considerable number of cases presenting with chronic watery diarrhea. Colonoscopy with biopsy provided the definitive diagnosis in $41 \%$ of patients which proves the importance of this procedure as part of the work up in chronic diarrhea while Shah et $\mathrm{a}^{12}$ found that colonoscopy with biopsy yielded the diagnosis in $31 \%$ of their cases.

UC is thought to be a rare chronic inflammatory bowel disease in developing countries.

Though it has been widely discussed in Western countries and been considered as a rare disease among Asian countries. ${ }^{13,14,15}$ In recent decades, studies from countries with low prevalence and incidence rates of UC have surfaces and redefines the whole epidemiology of UC..$^{10,11}$

A study carried out by Garg et $\mathrm{al}^{12}$ found ulcerative colitis in 18 patients out of 71 cases i.e. $25 \%$ of the sample size. But this study was done quite some time before.

However, the present study confirms the existence of ulcerative colitis with a frequency of $16.7 \%$ (20 patients out of 120). The results were almost similar to the study by Sood et al. ${ }^{16}$ This is quite high in comparison to the relative frequency of $6 \%$ in a stu Recent reviews from China, Japan, South Korea, Singapore and India have shown an increase in incidence and prevalence of UC, while incidence of Crohn's disease is still low. dy at Al-Khobar, Saudi Arabia done by Satti et al. ${ }^{17}$

Most $(60 \%)$ of the patients of UC had vegetarian diet with all having milk as a part of their diet. Egg and meat formed the part of diet in all non-vegeterians. Wheat, maize, cow's milk, refined sugar, fruit and vegetables are the risk factors that have been suggested as perhaps influencing the development of UC.

\begin{tabular}{|l|l|l|l|}
\hline Study & Total no. of patients & Diagnosed as ulcerative colitis & Percentage \\
\hline Garg et al & 71 & 18 & $25 \%$ \\
\hline RAFI UD DIN et al & 50 & 20 & $40 \%$ \\
\hline A Sood et al & 147 & 23 & $15.64 \%$ \\
\hline Present Study & 120 & 20 & $16.7 \%$ \\
\hline
\end{tabular}

ITB has been somewhat neglected by researchers, although it is increasing due to HIV co-infection. It is a particular problem in some localities, possibly due to the genetic characteristics of host and pathogen, plus socioeconomic factors. In resource-poor countries diagnosis will continue to be mainly by clinical presentation, so a high index of suspicion is required. Several sophisticated imaging and detection techniques are available, but molecular methods require validation for ITB. The diagnosis of tuberculosis is based on the demonstration of caseating granulomas, but many granulomas may not show caseation. Some studies have reported non-caseating granulomas in patients with tuberculosis.

In this study, 6 of 9 cases $(66.66 \%)$ of intestinal tuberculosis showed granulomas, while the rest of the cases were suspected as intestinal tuberculosis depending upon the clinical presentation and radiologic findings.

Microscopic colitis occurs more frequently between age 50-70 years. However children and adolescents may be affected presenting with similar clinical picture. Its frequency of occurrence in patients with chronic watery diarrhea is $0.3 \%-5 \%$ with an estimated incidence of 1.8 cases $/ 1000,000$ population in north

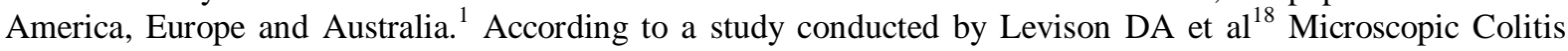
accounts for approximately $10 \%$ of patients presenting with chronic diarrhea. In a study conducted by Bogomoletz $\mathrm{WV}^{128}$ and et al in North America the prevalance of lymphocytic and collagenous colitis was found to be much higher (64 and 36/100000) respectively than in a study conducted by Shah RJ Europe (15.7 and $14.4 / 100000){ }^{12}$ While in our study we registered only two cases $(1.7 \%)$ of microscopic colitis, one of a lymphocytic type and the other of collagenous type.

This case of collagenous colitis was encountered in a middle aged female with a previous history of similar clinical presentations (Chronic watery diarrhea, intermittent pain in abdomen and no significant radiological and colonoscopic 
findings). She was diagnosed clinically as a case of irritable bowel syndrome and was subsequently treated, but with minimal improvement in symptoms. Later on, biopsies were obtained from different sites of the colon during colonoscopy and histopathologically examined. Histopathological picture revealed significant increase in the collagen band just below the mucosal layer which was evident on further work-up with special staining by Masson's Trichome Stain. The thickness was measured, which came out to be $>10$ micron in thickness. Along with the increase in collagen band, few other microscopic features like increased intraepithelial lymphocytes, entrapment of superficial capillaries were also seen which confirmed the diagnosis of collagenous colitis. These findings were similar to previous studies by Lazenby et al, Tagkalidis P et al and Falodia $\mathrm{S}$ et al in different studies. ${ }^{19}$ Smoking was found to be significant associative factor for causation of the disease. One case of lymphocytic colitis was encountered in our study in a 34 year old male who had symptoms consistent with irritable bowel syndrome (chronic watery diarrhea, intermittent pain in abdomen, abdominal discomfort). On colonoscopic examination no significant findings were seen. Biopsies were taken from different sites of the colon and after routine processing and staining, histo-pathological examination revealed an increase in intra-epithelial lymphocytes in the mucosal lining. We performed immuno- histochemical marker, CD3 to highlight the intra-epithelial lymphocytes which are basically T-lymphocytes. These highlighted lymphocytes were then counted. Ratio of lymphocytes per 100 columnar cells was obtained, which came out to be 35/100 in our case. No other histo-pathological abnormalities were found. These features along with clinical findings combined, prompted the diagnosis of lymphocytic colitis.

\section{Conclusions:}

All the patients presenting with chronic watery diarrhea should be evaluated thoroughly with detailed history, clinical examination and colonoscopy with biopsy wherever possible.

Microscopic colitis has become an emerging cause of chronic watery diarrhea and is increasing in incidence day by day, but very few studies have been done or published in the literature in Asia, especially India. Due to ignorance or under-diagnosis of the disease, the adequate treatment modalities cannot be well planned and can lead to serious complications like inflammatory bowel disease, malignancies or even death. So there's a need for more research on microscopic colitis.

Intestinal TB has been somewhat neglected by researchers, although it is increasing due to HIV coinfection. It is a particular problem in some localities, possibly due to the genetic characteristics of host and pathogen, plus socioeconomic factors. In resource-poor countries diagnosis will continue to be mainly by clinical presentation, so a high index of suspicion is required. Several sophisticated imaging and detection techniques are available, but molecular methods require validation for Intestinal TB.

Several sophisticated imaging and detection technique Inflammatory bowel diasease (Ulcerative Colitis and Crohn's disease) continue to increase in their incidence, especially in recent years as personal and dietary habits are fast changing with ever-changing life styles.

\section{References:}

[1]. Bonis PAL, LaMont JT. Approach to the patient with chronic diarrhea-I. In: Rose BD, editor. UpToDate(computer program), Wellesley MA: UpToDate; 2005.

[2]. Talley NJ, O'Keefe EA, Zinsmeister AR, Melton LJ 3d. Prevalence of gastrointestinal symptoms in the elderly: a population based study. Gastroenterology 1992; 102:895.

[3]. Talley NJ, Zinsmeister AR, Van Dyke C, Melton LJ 3d. Epidemiology of colonic symptoms and the irritable bowel syndrome. Gastroenterology 1991; 101:927.

[4]. Sandler RS, Stewart WF, Liberman JN. Abdominal pain, bloating, and diarrhea in the United States: prevalence and impact. Dig Dis Sci 2000; 45:1166.

[5]. Ahlquist DA, Camiilleri M. Diarrhea and constipation In: Kasper DL, Braunwald E, Fauci AS, Hauser SL,Longo DL, Jameson JL et al. Harrison's Principles of Internal Medicine 16th ed. USA: McGraw-Hill, 2005: 224-232.

[6]. Al-Bayatti SM. Etiology of chronic diarrhea. Saudi Med J, 2002; 23: 675-9.

[7]. Garg PK, Singh J, Dhali GK, Mathur M, Sharma MP. Microscopic colitis is a cause of large bowel diarrhea in North India. J Clin Gastroenterol, 1996; 22:11-5.

[8]. Read NW, Krejs GJ, Read MG, Santa Ana CA, Morawski SG, Fordtran JS. Chronic diarrhea of unknown origin. Gastroenterology 1980; 78: 264-271.

[9]. Levison DA, Lazenby AJ, Yardley JH. Microscopic colitis cases revisited. Gastroenterology 1993; 105: 1594-1596

[10]. Lindstrom CG. 'Collagenous colitis' with watery diarrhoea-a new entity? Pathol Eur 1976; 11: 87-89.

[11]. Abdo AA, Beck P. Diagnosis and management of microscopic colitis. Can Fam Physician.2003; 49:1473-1478.

[12]. Shah RJ, Fenoglio-Preiser C, Bleau BL, Gianella RA. Usefulness of colonoscopy with biopsy in the evaluation of chronic diarrhea. American J Gastroenterology 2001; 96:1091-95.

[13]. Thia KT, Loftus EV Jr, Sandborn WJ, Yang SK. An update on the epidemiology of inflammatory bowel disease in Asia. Am J Gastroenterol 2008;103:3167-82.

[14]. Hou JK, El-Serag H, Thirumurthi S. Distribution and manifestations of inflammatory bowel disease in Asians, Hispanics, and African Americans: a systematic review. Am J Gastroenterol 2009;104:2100-9

[15]. Goh K, Xiao SD. Inflammatory bowel disease: a survey of the epidemiology in Asia. J Dig Dis 2009;10:1-6.

[16]. Sood A, Midha V, Sood N, Bhatia AS, Avasthi G: Incidence and prevalence of ulcerative colitis in Punjab, North India. Gut 2003;52:15871590

[17]. Satti M, Al-Quorain A, Al-Gindan Y, Al-Hamdan A. Chronic idiopathic ulcerative colitis in Saudi Arabia:a clinicopathological study of 76 cases. Ann Saudi Med 1996;16(6):637-40.

[18]. Levison DA, Lazenby AJ, Yardley JH. Microscopic colitis cases revisited. Gastroenterology 1993; 105: 1594-1596.

[19]. Abdul Karim A S, Burgart L J, et al. Etiology of non responsive celiac disease ;results of a systematic approach. Am. J of Gastroenterol 2002;97:2016-21

[20]. Ahlquist DA, Camiilleri M. Diarrhea and constipation In: Kasper DL, Braunwald E, Fauci AS, Hauser SL, Longo DL, Jameson JL et al. Harrison's Principles of Internal Medicine 16th ed. USA: McGraw-Hill, 2005: 224-232. 